\title{
The availability and
}

\section{age-appropriateness of medicines authorized for \\ children in the Netherlands}

\author{
Diana A. van Riet-Nales, ${ }^{1,2}$ Karin E. de Jager, ${ }^{2}$ Alfred F.A.M. Schobben, ${ }^{2}$ \\ Toine C.G. Egberts ${ }^{2,3} \&$ Carin M.A. Rademaker ${ }^{3}$ \\ ${ }^{1}$ National Institute for Public Health and the Environment (RIVM), Centre for Quality of Chemical Phar- \\ maceutical Products, Bilthoven, ${ }^{2}$ Utrecht University, Faculty of Science, Utrecht Institute for Pharmaceu- \\ tical Sciences (UIPS), Department of Pharmacoepidemiology and Clinical Pharmacology, Utrecht and \\ ${ }^{3}$ University Medical Centre Utrecht, Department of Clinical Pharmacy, Utrecht, the Netherlands
}

\section{Correspondence}

Ms Diana A. van Riet-Nales Pharm.D, National Institute for Public Health and the Environment (RIVM), Centre for Quality of Chemical Pharmaceutical Products (KCF), P.O. Box 1, Mailbox 40, 3720 BA Bilthoven, the Netherlands.

Tel.: +31 302744215

Fax:+3130274 4462

E-mail:diana.van.riet@rivm.nl

Keywords

child, dosage forms, drug approval, excipients, medicine

\section{Received}

17 August 2010

Accepted

24 March 2011

Accepted Article

8 April 2011

\section{WHAT IS ALREADY KNOWN ABOUT THIS SUBJECT}

- Children are entitled to safe, efficacious, child and parent friendly (i.e. age-appropriate) medicines. However, off-label and unlicensed paediatric prescription rates in hospital range from $36 \%$ (surgical and medical wards) to $93 \%$ (neonatal wards), which indicates a general lack of age-appropriate medicines for children. In 2007, the European Union issued the Paediatric Regulation aiming at better medicines for children by, for example, increasing the number of authorized paediatric medicines.

\section{WHAT THIS STUDY ADDS}

- This study reviews the availability and age-appropriateness of medicines for children in the Netherlands, herewith providing a baseline for an estimation of the effect of the European Paediatric Regulation in the near future. This study also provides a tool for the evaluation of the child authorization status of medicines on the basis of the information in the Summary of Product Characteristics (SPC) and for the assessment of key aspects of the age-appropriateness of paediatric formulations.

\section{AIM}

To study the number of medicines and active chemical entities that are authorized and commercially available for children in the Netherlands and to evaluate the age-appropriateness of the available paediatric medicines.

\section{METHODS}

The availability of paediatric medicines and active chemical entities was studied with the help of a Dutch medicines database and the Summary of Product Characteristics. Medicines were categorized with respect to their route of administration, type of oral dosage form and therapeutic category. The age-appropriateness was assessed on three aspects: dose capability, suitability of the dosage form and inclusion of potentially harmful excipients.

\section{RESULTS}

Three thousand five hundred and forty-two paediatric medicines containing 703 different active chemical entities were identified. This equalled half of all the medicines and chemical entities available for human use. The percentage of paediatric medicines increased with age and varied for the route of administration from $22 \%$ (dermal) to $81 \%$ (inhalation) and for the therapeutic category from $11 \%$ (uro-genital, sex hormones) to $89 \%$ (anti-parasites). The appropriateness of the paediatric medicines with respect to their authorization status, dose capability and dosage form increased with age from 27-88\%. Fifty-two percent of all oral paediatric liquid formulations contained a potentially harmful excipient.

\section{CONCLUSION}

This study confirms the limited availability of paediatric medicines for a broad range of therapeutic areas and shows that paediatric medicines may not be age-appropriate, even if authorized. While confirming the need for a legislative incentive, the results also provide baseline information for an estimation of the effect of the European Paediatric Regulation in the near future. 


\section{Introduction}

In order to provide medical care to children, physicians often have to resort to a prescription for unauthorized medicinal drug products because there are no suitable, authorized medicines available [1-8]. However, in January 2007 , the Paediatric Regulation came into force in the European Union (EU) [9]. This regulation aims to facilitate the development and accessibility of authorized paediatric medicines in Europe by the application of multiple strategies. One of these strategies obliges industry to plan clinical trials in children at an early stage of the development of medicines containing a new active substance, unless a waiver or deferral has been granted. The same requirement applies to the development of a new indication for existing medicinal drug products. As clinical trials and marketing authorizations take a substantial amount of time, the real effect of the Paediatric Regulation on the availability of authorized, paediatric medicines and off-label and unauthorized paediatric prescription rates in Europe is still awaited $[10,11]$.

Recent studies in Australia, New Zealand, the USA and the UK showed a limited availability of medicines for children, thereby emphasizing the need for legislative incentives like the recently introduced EU Paediatric Regulation $[1-5,8,12,13]$. The information from the UK study can, moreover, be used as baseline information for an estimation of the effect of this Regulation in the near future. However, it would be better if such an evaluation would be based on baseline information from several European countries. In order to adjust for the availability of comparable medicines that add little to covering children's therapeutic needs (e.g. generic medicines), such an evaluation would preferably also involve a review of the availability of the number of active chemical entities in medicines authorized for children.

The design of currently authorized paediatric medicines is not always optimal $[9,14,15]$. This is understandable as scientific evidence on the impact of pharmaceutical technology aspects of paediatric medicines on child patient outcomes is scarce [16]. In fact it is well known that some medicines for children contain potentially harmful excipients $[17,18]$. Moreover, tablets have been authorized for children below the age of 6 years, even though they may be unable to swallow tablets [19]. Thus, it is vital to study to what extent authorized medicines are really adequate for use in children. Therefore, the first objective of this study was to identify the availability of medicines and active chemical entities authorized for children in the Netherlands. The second objective was to evaluate the age-appropriateness of the identified paediatric medicines towards their ability to provide for the recommended dose (dose capability), the suitability of their dosage form for the indicated target age groups and the inclusion of potentially harmful excipients.

\section{Methods}

\section{Availability of paediatric medicines}

All authorized and commercially available medicines for human use in the Netherlands and their active chemical entities were identified with help of the Z-index on 6 May 2009. The Z-index is a monthly updated national database containing information on all medicines for sale on the Dutch market. Each entry in the Z-index (further referred to as each medicine) corresponds with a unique medicinal drug product. These drug products relate to a single strength or dosage form, to all filling volumes of liquid preparations in the same concentration or to all filling weights of powders for reconstitution for solution of the same composition [17]. Homeopathic medicines, herbal preparations and radionuclide generators were excluded, and parallel import products were omitted as they add no new treatment possibilities. Relevant characteristics were extracted for each of the included medicines. The medicines were then categorized according to their route of administration, e.g. oral, rectal. Oral medicines were further categorized into the different oral dosage forms and tablets and capsules into their different types.

The Z-index did not allow direct extraction of the commercially available medicines and active chemical entities intended for children. Therefore, a national electronic Medicines Compendium compiled by the Scientific Institute of Dutch Pharmacists (Informatorium Medicamentorum) was examined to identify all active substances where the sections 'dosing information' or 'method of administration' contained a word suggesting use in children [18]. Thereafter the related medicines were selected in the Z-index and the child authorization status of the selected medicines was manually verified by examination of sections 4.1 'therapeutic indications' and 4.2 'posology and method of administration' of the Summary of Product Characteristics (SPC) [20].The information in these SPC sections was examined according to newly developed criteria (Appendix 1). The selection methodology was verified by evaluation of the SPCs of a random sample of 400 medicines in the Z-index for which the Informatorium Medicamentorum did not suggest the use of the active substance in children. The evaluation showed that $96 \%$ of these medicines were indeed for adults only i.e. $4 \%$ misclassification. Half of the misclassified medicines $(2 \%)$ were only indicated for children from the age of 15 or 16 years.

\section{Age-appropriateness}

The age-appropriateness of the included paediatric medicines was evaluated by investigating three key aspects. The first aspect investigated was whether the recommended doses of the sampled medicine (as per its SPC) could be given to children, i.e. if the medicine was dose capable (Appendix 1). The dose capability was studied in a sample of 400 authorized, paediatric medicines for each of the five target age-categories: term newborn infants ( 0 to 27 days), 
infants and toddlers ( 28 days to 23 months), children 2 to 5 years, children 6 to 11 years and children 12 to 17 years [21]. The sample was stratified for the type of marketing authorization (European or national). If the recommended dose could not be given with the sampled medicine (e.g. a $375 \mathrm{mg}$ amoxicillin tablet cannot be used to deliver a $125 \mathrm{mg}$ dose), it was verified whether this dose could be given by another paediatric medicine containing the same active chemical entity and applying the same route of administration (e.g. amoxicillin $125 \mathrm{mg} / 5 \mathrm{ml}$ oral liquid can be used instead).

The second aspect investigated was whether the dosage form of the sampled medicine was suitable for use in children. The same sample of 400 paediatric medicines and the same age-categories were studied. If the dosage form was considered as 'not suitable' (e.g. a $250 \mathrm{mg}$ capsule for a 1 year old child), it was verified whether an alternative dosage form utilizing the same route of administration (e.g. a $250 \mathrm{mg} / 5 \mathrm{ml}$ oral liquid) could be identified. The suitability of the dosage forms was evaluated according Table 3.1 of the 'Reflection paper on formulations of choice for the paediatric population' applying the criterion that a value of 4 or 5 represented sufficient suitability and applying the additional criteria as described in Appendix 1 [15]. Medicines were considered age-appropriate with respect to their dose and dosage form when either the medicine itself or any of its alternatives fulfilled the applied criteria. Otherwise, the medicines were considered age-inappropriate.

The third aspect examined related to the inclusion of potentially harmful excipients in medicines for children.
These excipients were selected on the basis of the aforementioned reflection paper: benzyl alcohol, benzoic acid/sodium benzoate, methylparahydroxybenzoate, butylparahydroxybenzoate, propylparahydroxybenzoate, ethanol, propylene glycol and synthetic colouring agents. In view of the nature of these excipients, their inclusion in medicines for paediatric use was studied in two other samples, namely a sample consisting of all oral liquid paediatric medicines and a sample consisting of all parenteral paediatric medicines. In case the preparations contained a potentially harmful excipient, it was verified whether the use of this excipient could be avoided by using another oral liquid or parenteral preparation containing the same active chemical entity. The ageappropriateness of medicines containing a potentially harmful excipient was considered questionable, especially when alternative medicines showed that their inclusion could be avoided.

\section{Data analysis}

Descriptive statistics were performed through Microsoft Excel XP and SPSS version 17.

\section{Results}

\section{Availability}

The availability of medicines and active chemical entities for children is described in Table 1, as well as the availability of all medicines for human use.

Evaluation of the SPCs of medicines suggesting use in children revealed that 3542 (48\%) of the 7410 medicines

\section{Table 1}

Availability of medicines and active chemical entities for children

\begin{tabular}{|c|c|c|c|c|c|c|}
\hline & \multicolumn{2}{|c|}{ Authorized medicines } & \multicolumn{4}{|c|}{ Authorized active chemical entities } \\
\hline & $\begin{array}{l}\text { Paediatric } \\
\text { medicines }\end{array}$ & $\begin{array}{l}\text { All medicines for } \\
\text { human use }\end{array}$ & $\begin{array}{l}\text { Percentage } \\
\text { paediatric } \\
\text { vs. all medicines }\end{array}$ & Children & $\begin{array}{l}\text { All chemical } \\
\text { entities for } \\
\text { human use }\end{array}$ & $\begin{array}{l}\text { Percentage } \\
\text { paediatric vs. all } \\
\text { chemical entities }\end{array}$ \\
\hline Route of administration (total) & 3542 & 7410 & $48 \%$ & $703+$ & $1490+$ & $47 \%$ \\
\hline Oral & 2247 & 4933 & $46 \%$ & 357 & 726 & $49 \%$ \\
\hline Parenteral & 788 & 1439 & $55 \%$ & 339 & 623 & $54 \%$ \\
\hline Dermal & 71 & 317 & $22 \%$ & 23 & 144 & $16 \%$ \\
\hline Ear/eye & 52 & 190 & $27 \%$ & 28 & 79 & $35 \%$ \\
\hline Inhalation & 138 & 170 & $81 \%$ & 28 & 34 & $82 \%$ \\
\hline Rectal & 135 & 180 & $77 \%$ & 20 & 47 & $43 \%$ \\
\hline Nasal & 101 & 127 & $80 \%$ & 13 & 19 & $68 \%$ \\
\hline Other & 10 & 54 & $19 \%$ & 15 & 39 & $38 \%$ \\
\hline Oral dosage form (total) & 2247 & 4933 & $46 \%$ & $357 \dagger$ & $726+$ & $49 \%$ \\
\hline Tablets & 1422 & 3620 & $39 \%$ & 237 & 592 & $40 \%$ \\
\hline Capsules & 334 & 633 & $53 \%$ & 78 & 162 & $48 \%$ \\
\hline Oral liquid preparations* & 400 & 495 & $81 \%$ & 133 & 167 & $80 \%$ \\
\hline Powder/granules & 65 & 93 & $70 \%$ & 22 & 31 & $71 \%$ \\
\hline Oral drops & 11 & 17 & $65 \%$ & 9 & 15 & $60 \%$ \\
\hline Others & 15 & 75 & $20 \%$ & 9 & 44 & $20 \%$ \\
\hline
\end{tabular}

*Oral liquid preparations consisted of all medicines that are liquid when applied (e.g. effervescent tablets were also considered as oral liquid preparations).

+Some active chemical entities were available in more than a single dosage form. 


\section{Table 2}

Medicines and active chemical entities for children per therapeutic category

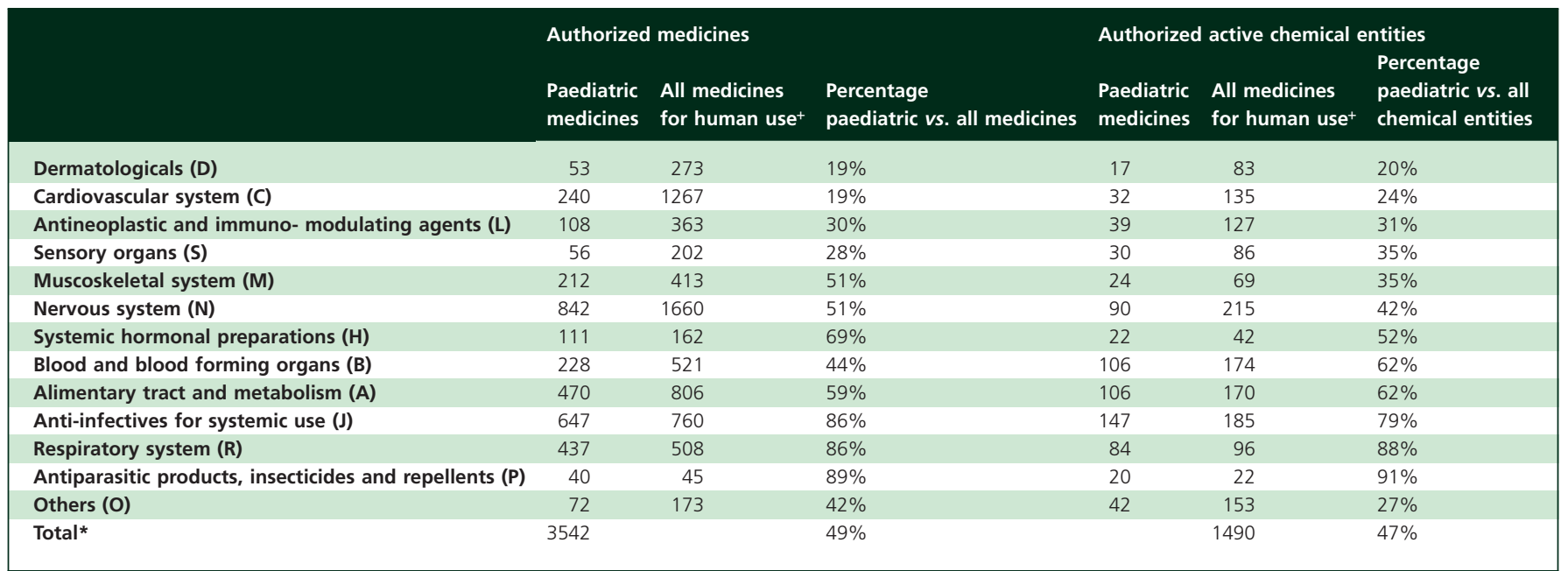

*One chemical entity may relate to several ATC codes.

for human use and 703 (47\%) of the 1490 active substances for human use were authorized for one or more paediatric age groups. In 51 (7\%) SPCs the child authorization status could not be deducted due to unclear or conflicting information.

Most of the medicines for children were for oral $(n=2247$ of $3542,63 \%)$ or parenteral use $(n=788$ of 3542 , $22 \%$ ). The percentage of oral medicines for children vs. all oral medicines is $46 \%(n=2247$ of 4933$)$ and the percentage of parenteral medicines for children vs. all parenteral medicines $55 \%$ ( $n=788$ of 1439). The largest percentage of medicines for children vs. all medicines was identified for medicines for inhalation (81\%), nasal (80\%) and rectal use (77\%) and the smallest for medicines for dermal use (22\%).

The most favourite oral dosage form in children were tablets ( $n=1422$ of $2247,63 \%)$. Oral liquid preparations ( $n=400$ of $2247,18 \%$ ) and capsules ( $n=334$ of $2247,15 \%$ ) were available to a lesser extent, whereas powder/granules were the least favourite dosage form ( 65 of $2247,3 \%$ ). The percentage of tablets for children vs. all tablets was 39\% ( $n=1422$ of 3620), the percentage of capsules for children vs. all capsules $53 \%$ ( $n=334$ of 633 ) and the percentage of oral liquid preparations for children vs. all oral liquid preparations $81 \%$ ( $n=400$ of 495$)$.

The majority of tablets for children were uncoated $(n=1005,71 \%)$. Film-coated and modified release tablets were available to a lesser extent $(n=250,18 \%$ and $n=120$, $8 \%$, respectively). Tablets were least often available as melting and chewing tablets $(n=16,1 \%$ and $n=15,1 \%$, respectively). The majority of capsules were hard and immediate release capsules ( $n=276,83 \%)$. Hard, modified release capsules and soft capsules were more scarce ( $n=37,11 \%$ and $n=21,6 \%$, respectively). The percentage of the different types of tablets for children vs. all tablets varied between 36\% (melting tablets) and 45\% (chewing tablets) and for capsules between 28\% (hard, modified release) and $91 \%$ (soft capsules).

Data on the anatomical therapeutic chemical classification (ATC) code of the included medicines and active chemical entities for children are described in Table 2. The percentage of medicines for children vs. all medicines varied from $11 \%$ for the genito-urinary system and sex hormones (ATC $=G), 19 \%$ for the dermatologicals (ATC $=$ D) and $19 \%$ for the cardiovasculair system $($ ATC $=C$ ) to $86 \%$ for the respiratory system (ATC $=\mathrm{R}), 86 \%$ for the antiinfectives for systemic use (ATC $=J$ ) and $89 \%$ for the antiparasitic products, insecticides and repellents $($ ATC $=P$ ). Evaluation on the basis of the active chemical entities showed a similar pattern.

\section{Age-appropriateness}

The random sample of 400 medicines studied for this purpose equalled $11 \%$ of all paediatric medicines. Ninety per cent of the sampled medicines were granted a Dutch Marketing Authorization and 10\% a European Marketing Authorization. The sample contained 83 unique chemical entities, which equalled $23 \%$ of all active chemical entities in paediatric medicines. Detailed analysis showed that our sample was representative concerning the route of administration and type of oral dosage form (data not shown).

Data on the child authorization status per target age group, the ability to provide for the recommended dose (dose capability) and the suitability of the dosage form are depicted in Figure 1. Using this first sample of 400 paediatric medicines, the percentage of authorized medicines in the population is estimated as $37 \%(95 \% \mathrm{Cl} 32.2 \%, 41.6 \%)$ in the $0-27$ days group and as $96 \%(95 \% \mathrm{Cl} 93.3 \%, 97.5 \%)$ in the 12-17 years group. In addition, the percentage of authorized and dose capable medicines in the population is estimated as $30 \%(95 \% \mathrm{Cl} 25.5 \%, 34.4 \%)$ in the $0-27$ days 


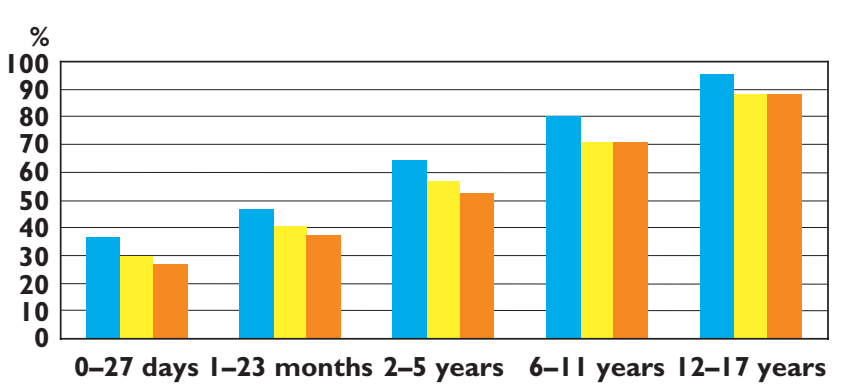

\section{Figure 1}

Age-appropriateness of medicines for children ( $n=400,100 \%)$. Authorized for paediatric use ( $\square$ ); authorized and able to provide for the recommended dose (dose capable) ( $\square$ ); authorized, dose capable and having a suitable dosage form ( $\square$ )

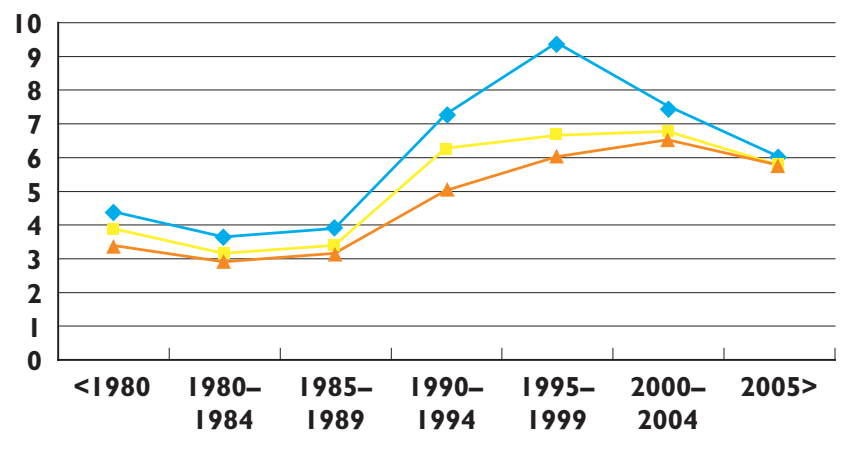

Date of marketing authorization

\section{Figure 2}

Percent of paediatric medicines in the sample $(n=400)$ 1-23 months. Authorized $(-\bullet)$; authorized and dose capable $(-)$; authorized, dose capable and having a suitable dosage form $\left({ }^{-}\right)$

group and as $88 \%(95 \% \mathrm{Cl} 84.3 \%, 90.7 \%)$ in the $12-17$ years group. Finally, the percentage of authorized and dose capable medicines with a suitable dosage form in the population was estimated as $27 \%(95 \% \mathrm{Cl} 22.7 \%, 1.3 \%)$ in the $0-27$ days group and as $88 \%(95 \% \mathrm{Cl} 84.3 \%, 90.7 \%)$ in the 12-17 years group. The percentage of medicines registered for children has increased over the years since 1980. However the age-appropriateness of medicines towards their authorization status, dose capability and suitability of the dosage form gradually improved only with more recent years of marketing authorization (Figure 2, example for age 1-23 months, other ages gave similar results).

Data on the potential harmfulness of the excipients are described in Table 3. Fifty-two percent of all oral liquid paediatric medicines contained one or several of the investigated potential harmful excipients. For $22 \%$ an alternative liquid was available with the same active chemical entity, but not the potentially harmful substance. For $17 \%$ an alternative liquid with a lower number of potentially harmful substances was available.
Table 3

Potential harmful excipients in medicines for children

\begin{tabular}{|lrrrr|}
\hline & $\begin{array}{l}\text { Oral liquid } \\
\text { preparations } \\
\text { Potential harmful excipient }\end{array}$ & \multicolumn{1}{l}{$\boldsymbol{n}(\mathbf{4 0 0 )}$} & $\begin{array}{l}\text { Parenteral } \\
\text { preparations } \\
(\boldsymbol{n}=\mathbf{7 8 8})\end{array}$ \\
\hline Benzyl alcohol & 1 & $0.3 \%$ & 29 & $4 \%$ \\
\hline Benzoic acid/sodium benzoate & 70 & $17 \%$ & 0 & $0 \%$ \\
\hline Methylparahydroxybenzoate & 77 & $19 \%$ & 9 & $1 \%$ \\
\hline Butylparahydroxybenzoate & 1 & $0.3 \%$ & 0 & $0 \%$ \\
\hline Propylparahydroxybenzoate & 45 & $11 \%$ & 1 & $0.1 \%$ \\
\hline Ethanol & 47 & $12 \%$ & 15 & $2 \%$ \\
\hline Propylene glycol & 43 & $11 \%$ & 11 & $1 \%$ \\
\hline Synthetic colouring agents & 31 & $8 \%$ & 0 & $0 \%$ \\
\hline Natural colouring agents & 48 & $12 \%$ & 0 & $0 \%$ \\
\hline Total* & 208 & $52 \%$ & 51 & $7 \%$ \\
\hline
\end{tabular}

*Total amount of oral liquid preparations and parenteral preparations containing one or more potential harmful excipients.

Seven percent of all parenteral preparations contained one or several of the investigated potentially harmful excipients.

\section{Discussion}

This study showed that 3542 medicines containing 703 active chemical entities were authorized and commercially available for some paediatric age categories. This equalled half of all the available medicines and active chemical entities for human use. Paediatric medicines were mostly intended for the oral and parenteral route of administration. The percentage of medicines for children was most favourable for anti-infectives, respiratory medicines and anti-parasitic products, insecticides and repellents and least favourable for genito-urinary medicines and sex hormones, dermal preparations and cardiovasculair agents. The percentage of authorized and dose capable medicines with a suitable dosage form increased with age.

Authorized medicines that are not marketed do not bring any benefit to children. Therefore, this study was conducted in a database containing information on the commercial availability of medicines, the Z-index [17]. The Z-index does not allow electronic identification of medicines for children and is not freely available. As this hinders public access to actual and relevant medical information, competent authorities are encouraged to enable easy and public access to the commercial availability of medicines for children.

The percentage of medicines for children as found in this study (48\%) deviates slightly from the percentages found in the UK (59\%), Australia (38\%), New Zealand (35\%) and the USA (54\%) $[1,2,4,5,8]$. This confirms that the limited availability of medicines for children is a global rather than regional problem. Data comparison of all these studies should, however, be considered in view of 
methodological differences. All studies were conducted in national databases applying tailored inclusion and exclusion criteria resulting in a potentially different output. Secondly, in all studies the child authorization status was determined on the basis of licensing information. However it was not clear how this was actually operationalized in the other studies. The criteria as employed in this study can be used as a basis for the establishment of international consensus on the criteria to be employed for the assessment of the child authorization status of (existing) medicines.

An overall $48 \%$ relative availability of medicines for children might theoretically still be sufficient to cover most of their common and therapeutic needs. However in view of our findings for age-appropriateness and the EMA priority list for studies into off-patent medicinal products [22] there is lack of appropriate products for children in a considerable number of therapeutic areas.

This study showed that the relative availability of tablets and capsules for children (39\% and 53\%, respectively) is limited when compared with oral liquid preparations and powders or granules $(81 \%$ and $70 \%$, respectively). This is likely due to the fact that tablets and capsules are generally considered suitable for older children only. Melting and chewing tablets are more likely to be taken at a younger age than uncoated, film-coated and modified release tablets [15]. However, their availability for children appears to be limited.

The development of medicines tailored for use in children implies that a specific active substance may need to be available in different dosage forms and strengths, i.e. as different medicinal drug products, in order to treat a broad patient population from birth into adulthood or old age. Although some strengths and dosage forms are only intended for a specific age group or dose, existing SPCS may relate to all patient groups and all dosing recommendations. Therefore, the dose capability and the suitability of the dosage form were considered taking account of any alternative, authorized, paediatric medicine.

The dose capability was considered a binominal criterion. A medicine is either dose capable or it is not. However, the suitability of the dosage form is not as absolute. First of all,the table in the EU reflection paper was not developed as a decision tree for the age-appropriateness of paediatric medicines, it was based on a limited number of data and it could only be used for an evaluation of the ageappropriateness of paediatric medicines by defining additional criteria (Appendix 1). Secondly, according to this table, tablets and capsules are only suitable from the age of 6 years. However, recent studies have shown that small tablets can be swallowed by young children [23]. Also, some capsules can be opened and their contents given as such.

The age-appropriateness of medicines with respect to their excipient composition is even less absolute; firstly, because this study related to a limited number of potentially harmful excipients, and secondly, because a final evaluation of the harmfulness of an excipient in a paediatric medicine for a specific target age group would require additional information on the concentration and maximum daily intake. However, this information is not publicly available through the SPC.

In SPCs referring to a range of strengths and dosage forms, it often remains unclear which of these strengths and dosage forms can be used to deliver the selected dose to children of a particular age. Such information may be relevant when choosing the most appropriate dosage form for a child, to avoid the intake of potentially harmful excipients by young children or to avoid the intake of an excessive excipient amount by older children which may result in side effects (e.g. a laxative effect by sorbitol). Pharmaceutical companies are therefore encouraged to provide clear information on the applicability of the different strengths and dosage forms to different patient agegroups.

Sturkenboom et al. investigated paediatric prescription rates by therapeutic category [24]. Combination of their data and ours showed that anti-infectives and respiratory medicines were frequently prescribed and also readily available, that dermal preparations were frequently prescribed but not readily available, and that anti-parasitic products were rarely prescribed, but widely available. Future studies should evaluate whether the low availability of paediatric medicines in some of the therapeutic areas is a problem in clinical practice. This evaluation should take account of the seriousness of the disorder (unpleasant vs. life-threatening) and the availability of other treatment possibilities. It is interesting to see if the real therapeutic needs of the children of Europe will be better covered after the introduction of the EU Paediatric Regulation, especially as this is still doubtful in the USA where incentives have been implemented to increase the number of commercially available paediatric medicines since 1997 [25-29].

It is not realistic to expect that all medicines for adults will also become available for children. The authors consider that in exceptional cases, industry-verified instructions for pharmacy compounded medicines together with public information on the dose-response relationships in children could also be considered sufficient. Such pharmacy compounded medicines could take the active chemical entity or the adult medicine as the starting point. Where relevant, the availability of an appropriate quality of the active substance should be guaranteed. In addition, the impact of pharmaceutical handling on the bio-availability of the pharmacy compounded medicines should be understood and controlled.

This study showed that medicines authorized for children may differ with respect to their ability to provide the recommended dose, the suitability of the dosage form and the inclusion of potential harmful excipients. Because innovator products have at least been authorized 10 yeas prior to their generic competitors and because the ageappropriateness of paediatric medicines is only gaining increased attention over the last decade, there is little 
reason to believe that the age-appropriateness of innovative medicines will generally be better than that of its generic competitors. Thus the different trade marks of a medicine i.e. generics may provide additional value to children.

Clinicians and pharmacists should consider ageinappropriate formulations as a cause for administration errors, lack of therapeutic compliance, suboptimal clinical effects and unexpected side effects. In order to reduce the risk of any such problems, they are encouraged to compare the different trade marks of a particular medicine when prescribing or dispensing medicines for children.

Paediatric medicines may not be interchangeable with adult medicines and even the different trade marks of a paediatric medicine may not be interchangeable when needed for a specific age category. Both aspects should be acknowledged by pharmacists when substituting medicines for children and by health technology assessors in reimbursement decisions.

The review of the licensing information in this study revealed that SPCs do not necessarily meet the current regulatory requirements, which have gradually increased over the last decades in order to provide health care professionals and patients with more extensive information. Industry and competent authorities are therefore encouraged to update any outdated SPC and to undertake measures resulting in a reformulation of currently authorized, but age-inappropriate medicines.

\section{Limitations}

The results of this study are determined by the selection date, the inclusion and exclusion criteria and the criteria for the evaluation of the child authorization status. However it is rather unlikely that alternative criteria would have a major impact on the main conclusions of this study.

This study evaluates the age-appropriateness of paediatric medicines with respect to three of its key pharmaceutical technology aspects. However, other pharmaceutical aspects, such as palatability, measuring device or user instruction, may be of equal importance to the child and its parent. The impact on safety and efficacy could not be evaluated in this study.

This study did not evaluate whether the available paediatric medicines were also reimbursed. However lack of (full) reimbursement may also hinder the actual access of children to age-appropriate medicines.

In conclusion, about half of all commercially available medicines or active chemical entities in the Netherlands are authorized for one or more paediatric age groups. In several therapeutic areas, the commercial availability of medicines for children is even lower. This is especially true for young children and neonates. Moreover, authorized paediatric medicines cannot be considered as ageappropriate per definition. Thus, children lag behind adults with respect to their pharmacotherapeutic treatment options. Consequently, age-appropriate and authorized medicines for children should become increasingly available in order to limit the use of off-label prescribed and unauthorized medicines, which may not be safe and efficacious. The effect of the EU Paediatric Regulation is to be closely followed towards this goal. The results of this study can be considered as baseline information for this purpose.

\section{Competing Interests}

Diana van Riet is a senior researcher at the National Institute for Public Health and the Environment (RIVM). Her work includes chemical pharmaceutical assessments by order of the Medicines Evaluation Board in the Netherlands (MEB). She is vice chair of the European Medicines Agency's (EMAs) Quality Working Party. Alfred Schobben is a member of the MEB and expert for the EMA. Toine Egberts is also an expert for the EMA. No other conflicts of interest apply.

\section{Financial disclosure}

This study was supported by a grant from the National Institute for Public Health and the Environment (RIVM) and the Medicines Evaluation Board in the Netherlands (MEB).

\section{Disclaimer}

The opinions in this article are only those of the authors. This article is not intended to reflect the opinion of the Medicines Evaluation Board in the Netherlands (MEB) nor any of the working parties or scientific committees of the European Medicines Agency (EMA).

\section{Appendix 1}

Interpretation of information in section 4.1 and 4.2 of the Summary of Product Characteristics (SPC)

\begin{tabular}{|c|c|}
\hline SPC & Comment \\
\hline \multicolumn{2}{|l|}{ Child authorization status } \\
\hline $\begin{array}{l}\text { General statement referring to } \\
\text { children }\end{array}$ & Target age group: $0-18$ years \\
\hline General statement 'juvenile' & TARGET age group: $0-18$ years \\
\hline 'Zuigeling' (sucking child) & target age group: 0-1 year \\
\hline 'Jongvolwassene' (young adult) & Target age group: $16-18$ years \\
\hline 'Adolescent' & Target age group: $12-18$ years \\
\hline $\begin{array}{l}\text { A recommended dose for a } \\
\text { specific age range }\end{array}$ & $\begin{array}{l}\text { Target age group: the specific age } \\
\text { range for dosing }\end{array}$ \\
\hline $\begin{array}{l}\text { A recommended dose for } \\
\text { children from } 0 \text { until the age } \\
\text { of } 12 \text { to } 17 \text { years and a } \\
\text { recommended dose for adults }\end{array}$ & Target age group: $0-18$ years \\
\hline $\begin{array}{l}\text { A recommended dose in } \mathrm{mg} \mathrm{kg}^{-1} \\
\text { without any further } \\
\text { information }\end{array}$ & Target age group: $0-18$ years \\
\hline $\begin{array}{l}\text { The medicine can be used from } \\
\text { a specific minimum weight }\end{array}$ & $\begin{array}{l}\text { The minimum weight is used to } \\
\text { calculate the equivalent minimum } \\
\text { age according the Dutch growing } \\
\text { curve for girls, lower line }\end{array}$ \\
\hline
\end{tabular}




\section{Appendix 1}

Continued

\begin{tabular}{|c|c|}
\hline SPC & Comment \\
\hline $\begin{array}{l}\text { A minimum age between } 0 \text { and } \\
18 \text { years and a minimum } \\
\text { weight }\end{array}$ & $\begin{array}{l}\text { The target age groups are only based } \\
\text { on the information towards age }\end{array}$ \\
\hline $\begin{array}{l}\text { The medicine is discouraged for } \\
\text { use in children or a specific } \\
\text { target age group, } \\
\text { nevertheless a recommended } \\
\text { dose is given }\end{array}$ & $\begin{array}{l}\text { The child classification according the } \\
\text { dosing instruction is applied }\end{array}$ \\
\hline $\begin{array}{l}\text { A reference to several medicines } \\
\text { (e.g. different strengths and } \\
\text { dosage forms) and several } \\
\text { target age groups, but it is } \\
\text { clearly stated which medicine } \\
\text { is suitable for which of the } \\
\text { target age groups. }\end{array}$ & $\begin{array}{l}\text { Each medicine: only those target age } \\
\text { groups which are specific for that } \\
\text { medicine; otherwise each medicine } \\
\text { all target age groups }\end{array}$ \\
\hline $\begin{array}{l}\text { The lower target age is not } \\
\text { consistent wit the lower } \\
\text { ranges of the adapted ICH } \\
\text { criteria (e.g. } 2.5 \text { years) }\end{array}$ & $\begin{array}{l}\text { The lower age range of the next } \\
\text { modified ICH group is applied }\end{array}$ \\
\hline $\begin{array}{l}\text { Ability to follow the authorized } \\
\text { posology ('dose capable') }\end{array}$ & \\
\hline $\begin{array}{l}\text { The dosage instruction refers to } \\
\mathrm{mg} / \mathrm{kg} \text {, however the medicine } \\
\text { contains a fixed quantity of } \\
\text { active substance }\end{array}$ & $\begin{array}{l}\text { The medicine is not considered dose } \\
\text { capable }\end{array}$ \\
\hline \multicolumn{2}{|l|}{$\begin{array}{l}\text { Suitability of the dosage form } \\
\text { ('suitable') }\end{array}$} \\
\hline Tablets & $\begin{array}{l}\text { - A single dose may involve } 2 \text { tablets } \\
\text { at the maximum } \\
\text { - A single dose may involve a halved } \\
\text { tablet, if } 1 \text { ) the tablet contains a } \\
\text { score line } 2 \text { ) the SPC does not state } \\
\text { that the scoring line is for } \\
\text { esthaetical reasons only; } 3 \text { ) the SPC } \\
\text { does not state that the tablet may } \\
\text { only be broken to facilitate the } \\
\text { intake of the full dose. } \\
\text { - If the SPC reads that the tablet may } \\
\text { be pulverized, than the tablet is } \\
\text { considered suitable for children } \\
\text { from } 1 \text { month }\end{array}$ \\
\hline Capsules & $\begin{array}{l}\text { - If the SPC states that the capsule } \\
\text { may be opened, then the capsule is } \\
\text { considered suitable for children } \\
\text { from } 1 \text { month }\end{array}$ \\
\hline Suppositories & $\begin{array}{l}\text { - A single dose involves one } \\
\text { suppository (no halves) }\end{array}$ \\
\hline Enemas & $\begin{array}{l}\text { - The minimum dosing volume is } \\
5 \mathrm{ml} \text {, whereas the maximum dosing } \\
\text { volume is } 150 \mathrm{ml}\end{array}$ \\
\hline Oral liquid preparations & $\begin{array}{l}\text { - The maximum dosing volume is } \\
5 \mathrm{ml} \text { for children aged below } 5 \\
\text { years } \\
\text { - The maximum dosing volume is } \\
10 \mathrm{ml} \text { for children aged from } 5 \text { to } \\
10 \text { years } \\
\text { - The minimum single dosing is } \\
0.2 \mathrm{ml}\end{array}$ \\
\hline
\end{tabular}

\section{REFERENCES}

1 Balakrishnan K, Grieve J, Tordoff J, Norris P, Reith D. Pediatric licensing status and the availability of suitable formulations for new medical entities approved in the United States between 1998 and 2002. J Clin Pharmacol 2006; 46: 1038-43.

2 Balakrishnan K, Tordoff J, Norris P, Reith D. Establishing a baseline for the monitoring of medicines availability for children in the UK: 1998-2002. Br J Clin Pharmacol 2007; 63: 85-91.

3 Ceci A, Felisi M, Baiardi P, Bonifazi F, Catapano M, Giaquinto C, Nicolosi A, Sturkenboom M, Neubert A, Wong I. Medicines for children licensed by the European Medicines Agency (EMEA): the balance after 10 years. Eur J Clin Pharmacol 2006; 62: 947-52.

4 Chui J, Tordoff J, Kennedy J, Reith D. Trends in accessibility to medicines for children in New Zealand: 1998-2002. Br J Clin Pharmacol 2004; 57: 322-7.

5 Chui J, Tordoff J, Reith D. Changes in availability of paediatric medicines in Australia between 1998 and 2002. Br J Clin Pharmacol 2005; 59: 736-42.

6 Cuzzolin L, Atzei A, Fanos V. Off-label and unlicensed prescribing for newborns and children in different settings: a review of the literature and a consideration about drug safety. Expert Opin Drug Saf 2006; 5: 703-18.

7 Kairuz TE, Gargiulo D, Bunt C, Garg S. Quality, safety and efficacy in the 'off-label' use of medicines. Curr Drug Saf 2007; 2: 89-95.

8 Young L, Lawes F, Tordoff J, Norris P, Reith D. Access to prescribing information for paediatric medicines in the USA: post-modernization. Br J Clin Pharmacol 2009; 67: 341-6.

9 European Union. Regulation (EC) No 1901/2006 of the European parliament and of the Counsil of 12 December 2006 on medicinal products for paediatric use and amending Regulation (EEC) No 1768/92, Directive 2001/20/EC, Directive 2001/83/EC and Regulation (EC) No 726/2004. Available at http://eur-lex.europa.eu/LexUriServ/ LexUriServ.do?uri=OJ:L:2006:378:0001:0019:EN:PDF (last accessed 15 December 2009).

10 Auby P. Pharmaceutical research in paediatric populations and the new EU Paediatric Legislation: an industry perspective. Child Adolesc Psychiatry Ment Health 2008; 2: 38.

11 Breitkreutz J. European perspectives on pediatric formulations. Clin Ther 2008; 30: 2146-54.

12 Ceci A, Felisi M, Catapano M, Baiardi P, Cipollina L, Ravera S, Bagnulo S, Reggio S, Rondini G. Medicines for children licensed by the European Agency for the Evaluation of Medicinal Products. Eur J Clin Pharmacol 2002; 58: 495-500.

13 Grieve J, Tordoff J, Reith D, Norris P. Effect of the paediatric exclusivity provision on children's access to medicines. $\mathrm{Br} \mathrm{J}$ Clin Pharmacol 2005; 59: 730-5.

14 Cohen R, de La Rocque F, Lecuyer A, Wollner C, Bodin MJ, Wollner A. Study of the acceptability of antibiotic syrups, suspensions, and oral solutions prescribed to pediatric outpatients. Eur J Pediatr 2009; 168: 851-7.

15 European Medicines Agency, Committee for Medicinal Product for Human Use. Reflection paper: formulations 
of choice for the paediatric population. Available at http://www.ema.europa.eu/docs/en_GB/document_ library/Scientific_guideline/2009/09/WC500003782.pdf (last accessed 1 January 2010).

16 Van Riet - Nales DA, Schobben AFAM, Egberts ACG, Rademaker CMA. Pharmaceutical technology aspects of oral pediatric drugs and patient outcomes: a systematic literature review. Clin Ther 2010; 5: 924-38.

17 Z-index BV. Z-index database. Available at http://www.z-index.nl (last accessed 6 May 2009).

18 KNMP kennisbank online. Informatorium Medicamentorum. Available at http://www.knmp.nl/kennisbankbrowser (last accessed May 2009).

19 Medicines Evaluation Board in the Netherlands. Database human medicines SPCs for active substance is levothyroxin. Available at http://www.cbg-meb.nl (last accessed 20 December 2009).

20 Coordination Group for Mutual Recognition and Decentralized Procedures and European Medicines Agency. Questions and answers on the paediatric regulation (regulation of the European parliament and of the Counsil (EC) No 1901/2006 as amended), Revision 4, November 2008. Available at http://www.hma.eu/uploads/ media/Q_As_Paed_Reg_2008_11_Rev4-Clean.pdf (last accessed 15 December 2009).

21 International Conference on Harmonisation. ICH tripartite guideline Clinical investigation of medicinal products in the paediatric popuation E11. Available at http://www.ich.org (last accessed December 15 2009).

22 European Medicines Agency. Revised priority list for studies into off-patent paediatric medicinal products for the $5^{\text {th }}$ call 2011 for the $7^{\text {th }}$ Framework Programme of the European Commission. Available at http://www.ema.europa.eu/docs/ en_GB/document_library/Other/2009/10/WC500004017.pdf (last accessed 7 December 2010).
23 Thomson SA, Tuleu C, Wong IC, Keady S, Pitt KG, Sutcliffe AG. Minitablets: new modality to deliver medicines to preschool-aged children. Pediatrics 2009; 123: e235-8.

24 Sturkenboom MC, Verhamme KM, Nicolosi A, Murray ML, Neubert A, Caudri D, Picelli G, Sen EF, Giaquinto C, Cantarutti L, Baiardi P, Felisi MG, Ceci A, Wong IC. Drug use in children: cohort study in three European countries. BMJ 2008; 337: 2245.

25 Boots I, Sukhai RN, Klein RH, Holl RA, Wit JM, Cohen AF, Burggraaf J. Stimulation programs for pediatric drug research: do children really benefit? Eur J Pediatr 2007; 166: 849-55.

26 One hundred and fifth Congress of the United States of America. Food and Drug Administration Modernization Act of 1997. Available at http://www.fda.gov/downloads/ Regulatorylnformation/Legislation/FederalFoodDrugand CosmeticActFDCAct/SignificantAmendmentstotheFDCAct/ FDAMA/FullTextofFDAMAlaw/UCM089145.pdf (last accessed 1 October 2009).

27 One Hundred Eights Congress of the United States of America. Pediatric Research Equity Act of 2003 (S.650). Available at http://www.fda.gov/downloads/Drugs/ DevelopmentApprovalProcess/DevelopmentResources/ UCM077853.pdf (last accessed 1 October 2009).

28 One Hundred Seventh Congress of the United States of America. Best Pharmaceuticals for Children Act (S.1789). Available at http://www.fda.gov/downloads/Drugs/ DevelopmentApprovalProcess/DevelopmentResources/ UCM049874.pdf (last accessed 1 October 2009).

29 One hundred tenth Congress of the United States of America. FDA Amendments Act of 2007 (H.R.3580). Available at http://www.fda.gov/Regulatorylnformation/Legislation/ federalfooddrugandcosmeticactfdcact/ significantamendmentstothefdcact/ foodanddrugadministrationamendmentsactof2007/default. htm (last accessed 1 October 2009). 